\title{
Accept or Reject? Predicting Ideation Outcomes through Enterprise Social Media
}

\author{
Nik Ahmad Rozaidi i, ${ }^{1,}$, Jennifer L. Gibbs ${ }^{1}$, and Julia Eisenberg ${ }^{2}$ \\ ${ }^{1}$ Rutgers University, New Jersey, USA \\ ${ }^{2}$ Pace University, New York, USA
}

\begin{abstract}
Implementing social media in the workplace may make it easier for employees to participate in knowledge sharing activities such as Q\&A and ideation. However, vetting the quality of answers and ideas becomes more complex when anyone in the company can contribute. Research on the use of social media for Q\&A has shown that certain characteristics and reputation algorithms can help determine the best answers. Less is known about the ideation process and the way it plays out in social media. This paper explores the use of enterprise social media (ESM) for ideation by employees in a large Russian organization distributed across nine time zones. In particular, we explore which characteristics of both ideas and their contributors predict whether ideas get accepted or rejected. Our analysis is based on logistic regression analysis of a sample of 488 ideas contributed in an ESM tool used in the organization as well as a content analysis of the types of ideas generated. Our results suggest that rather than being truly democratic and decentralized, ideation in ESM is driven by those in (or proximate to) positions of organizational power.
\end{abstract}

\section{Introduction}

Organizations need ideas to innovate. Ideas are solicited from a variety of internal and external sources. Employees are perhaps the most cost effective way to obtain ideas as they are experienced, knowledgeable, and accessible. For employees, the ability to participate in organizational decision-making is beneficial as it leads to greater employee satisfaction and productivity [1]. This is despite the paradox that the final decision remains in the hands of upper management [2]. The introduction of enterprise social media (ESM) and its increasing adoption within organizations may be expected to increase the level of employee participation in the ideation process, defined as the generation, development, and submission of ideas [3]. ESM has the potential to democratize participation by connecting employees without being constrained by geographical, functional, or hierarchical boundaries. Despite some resistance to ESM stemming from user perceptions and preferences that conflict with workplace norms and legitimacy [4.5.6], privacy and

\footnotetext{
*Corresponding author: nrozaidi@rutgers.edu
} 
impression management concerns related to "context collapse" [7,8] and increased demands on one's time and attention $[9,8]$, adopting organizations are finding that ESM affordances are enabling processes that were impossible or difficult before [10]. Employees can now connect more easily with co-workers and communicate across various organizational boundaries [11] as well as share and access knowledge from otherwise unknown colleagues $[12,13]$. This creates tremendous potential in terms of strengthening workplace ties and further enhancing the participatory climate in the organization. However, the extent to which ESM use is actually challenging traditional hierarchy, status, and power boundaries remains unclear.

In terms of ideation, ESM may provide unique affordances or possibilities for action $[14,15]$ such that ideas can be more easily produced in greater numbers by almost anyone with access to the platform. The lack of credentials and expertise of contributors however may cause the idea quality to be questioned, and may undermine management's ability to evaluate and make a decision on which ideas to accept. As many organizations are focusing on innovation as part of their strategy and as adoption of ESM becomes more widespread, we believe it is important to understand the factors that can facilitate social media-based decision-making, including the process for ideation.

The aim of this study is to understand factors that may predict whether an idea generated in ESM gets accepted or rejected. To address this question, we borrow from the literature on answer quality from social Q\&A sites, given the nascent use of social media for ideation. This paper contributes to the social media literature through its study of ideation as a consequence of the knowledge sharing aspect of the platform.

\section{Background and related work}

\subsection{Ideation in Enterprise Social Media}

We define ideation as a process of generation and development of ideas for problem solving. Ideation to us is a distinct concept, not to be confused with brainstorming or innovation. Brainstorming [16] is one of the techniques for ideation, while innovation is the broader process that includes ideation as a cornerstone activity and that which ends with the implementation of the chosen ideas [17]. Regardless, the goal of the ideation process is to produce as many good ideas as possible for subsequent selection and decision-making. The implementation of ESM in the workplace has created a novel forum for ideation to occur. While ESM is also a computer-mediated platform, there are a few key differences compared to traditional systems. Due to its broader reach to the whole organization and the likelihood that users are identifiable, ESM tools such as social network sites may afford greater and more egalitarian participation [18] that supports idea contribution, evaluation, and prioritization. ESM may also afford new connections (e.g. follower relationships) that transcend hierarchical, functional, and geographical boundaries [11] that further encourage participation in the ideation process. ESM also affords metavoicing [19] in which users can participate or express themselves in multiple ways in the ideation process, including commenting, liking, and following.

\subsection{Answer Quality in Social Q\&A Sites}

Social media tools provide a unique venue for both enacting and observing the ideation process. Community Q\&A sites like Yahoo Answers offer a way to publicly pose questions to a community of experts or knowledgeable users who are willing to spend time and effort to impart their knowledge on a subject. Even social network sites like Facebook are being used for Q\&A albeit among the network of friends [20]. These are alternatives for finding 
information online instead of using a search engine or emailing someone. For those providing the answers, there is often some benefit to be gained from providing a good answer, such as being recognized as an expert. However, there may also be an incentive to provide an answer, regardless of its quality, to earn points for participation. These incentives when combined with the openness of the platform mean that there is potential for spam, as providing feedback is not restricted to just those with the necessary expertise. To counter this, the one posting the inquiry can be requested to choose the best answer, or the community members can be asked to vote for it, but this is typically quite subjective.

As [21] found from their analysis of Yahoo Answers, the "best" answer in a community Q\&A site varies depending on question topic (or context and nature of question) and can be more socio-emotional than factual-centric. For example, in support forums, the best answers tend to be the most emphatic or caring; and in discussion forums, the best answers tend to agree with askers' opinions. In predicting the best answers, [22] identified 20 features that strongly predict answer quality. Among them are: answer length; number of up and/or down votes ("thumbs-up" or "thumbs-down") an answer receives; the fraction of answers picked as best answers; and the average number of answers received by the question. [21] used answer characteristics and user attributes to predict answer quality. Performing a logistic regression on the answer outcomes across three categories (programming, marriage, wrestling), they found that reply length and total number of answers were strong positive predictors while thread length and number of user replies were significant negative predictors. Based on a review of related research, we theorize that answer quality depends on the properties of the questions, the answers, and the askers/answerers. Because ideation on ESM shares a similar problem as social Q\&A in terms of finding the best contribution among many, it can be argued that the quality of ideas generated on social media is dependent on properties of both the ideas themselves as well as their contributors. We therefore ask: What factors predict whether an idea generated in ESM gets accepted or rejected?

\section{Methodology}

\subsection{Data collection}

A case study was performed on a company that had deployed an ESM application and used it for ideation. The company is a retail subsidiary of a multinational telecommunications company headquartered in Moscow, Russia that employed about 20,000 people in its corporate offices and retail outlets in approximately 1,000 cities throughout Russia. The company, TeleCom (a pseudonym), deployed an ESM application called TeleCom Life in Fall 2011 as part of a broader initiative to improve internal communication and knowledge sharing. The application enabled employees to create online profiles, find and articulate connections with co-workers by following them, and interact with others through the exchange of online messages or by "liking" them, among many other features. Employees' online activities were logged and stored in a file on a central server, which contained descriptive information about users (job title, department, and location) as well as data about when users posted messages, made comments, "liked" posts, and "followed" other users. The use of the ESM for ideation was undertaken through a section called Forum of Innovators. Employees (including management) were encouraged to visit this forum to post new ideas and/or comment on or "like" the ideas of others. Periodically, the management team would come in and review the ideas that had been posted and decide to flag them as either "accepted" or "rejected"; ideas carry the "new" flag by default. Winners were flown to Moscow for a meeting in which they received company recognition and some had the opportunity to be involved with further development of the idea. 
While we did not have direct access to the system, access was provided through a server $\log$ file containing metadata for activities from the entire first year of use of the system. The file was sanitized by removing personally identifiable information and texts of the posts, although the subject tags describing the posts, where provided, were retained. In order to facilitate the analysis of the log file, it was first converted into a MySQL database, its textual information machine-translated from Russian into English and verified by several native Russian speakers. Overall, the database contained 156,543 posts, 628,782 comments, 503,180 follower relationships, and 849,126 likes involving 17,192 users. Users were distributed across ten regions (Headquarters 11.0\%, Chernozem 1.3\%, Central 10.3\%, Far East 5.5\%, Moscow 9.0\%, Northwest 10.2\%, Siberia 9.3\%, South 10.7\%, Ural $14.2 \%$, Volga $18.5 \%$ ) and five hierarchical positions (top management $0.7 \%$, middle management $14.9 \%$, senior specialist $10.8 \%$, specialist $67.1 \%$, and support staff $6.6 \%$ ).

\subsection{Measures}

Of the 156,543 posts in the database, 3,245 posts were explicitly labeled as "ideas". Of these, 155 were accepted ideas, 333 were rejected, while the rest were "new" ideas as of the time the log data were collected. There was no data regarding when decisions about the ideas were made. The ideas with decisions were organized into the dependent variable of idea status (accepted versus rejected), with "new" ideas being excluded from the dataset as they were still pending, for a total $\mathrm{N}$ of 488 ideation posts. The independent variables were comprised of two major dimensions: idea attributes and contributor attributes. Idea attributes included duration (number of minutes from first post to last comment), number of likes, and number of comments. Contributor attributes included employee position (recoded into five categories: top management, middle management, senior specialist, specialist, and support staff), location (ten regions that were recoded into headquarters versus non-headquarters), expertise points within the system (from their activities on the ESM and from ratings by other users), number of followers, number of people followed, number of ideas contributed, and how many ideas were new, accepted, and rejected. Due to the large degree of variance and number of outliers, the variables for duration, number of likes, and number of followers were log transformed to standardize them.

\subsection{Data Analysis}

We tested our ability to predict which idea characteristics and contributor characteristics were correlated with the outcome of the ideation evaluation process. Given that our dependent variable (idea acceptance versus rejection) was binary, we conducted a logistic regression analysis on the two sets of variables.

\section{Findings}

\subsection{Inter-item correlation}

An inter-item correlation matrix revealed moderate yet significant correlations among many of the study variables, indicating that they were associated but that multi-collinearity was not an issue. In particular, idea status was significantly positively associated with number of accepted ideas $(\mathrm{r}=.51, \mathrm{p}<.001)$, number of followers $(\mathrm{r}=.34, \mathrm{p}<.001)$, number of likes $(\mathrm{r}=.32, \mathrm{p}<.001)$, duration of discussion $(\mathrm{r}=.28, \mathrm{p}<.001)$, position $(\mathrm{r}=$ $.10, \mathrm{p}<.05)$, and expertise level $(\mathrm{r}=.09, \mathrm{p}<.05)$, and it was negatively associated with number of ideas created $(\mathrm{r}=-.15, \mathrm{p}<.001)$. Number of comments and region were nonsignificant. Table 1 shows the inter-item correlations. 
Table 1. Inter-item Correlations among Study Variables ( $\mathrm{N}=488)$.

\begin{tabular}{|c|c|c|c|c|c|c|c|c|c|}
\hline Variables & 1 & 2 & 3 & 4 & 5 & 6 & 7 & 8 & 9 \\
\hline 1. Idea Status & -- & & & & & & & & \\
\hline 2. Duration of Discussion & $.28^{* * *}$ & -- & & & & & & & \\
\hline 3. Number of Likes & $.32^{* * 1}$ & $.41^{* * *}$ & -- & & & & & & \\
\hline 4. Number of Comments & .05 & $.36^{* * *}$ & $.51^{* * *}$ & -- & & & & & \\
\hline 5. Number of Followers & $.34^{* * *}$ & $.11^{* * *}$ & $.28^{* * *}$ & $.09^{* *}$ & - & & & & \\
\hline 6. Expertise Level & $.09^{*}$ & .02 & $.13^{* * *}$ & $.06^{* *}$ & $.17^{* * *}$ & -- & & & \\
\hline 7. Number of Ideas Created & $-.15^{* *}$ & $-.10^{* * *}$ & $-.05^{* *}$ & -.02 & $.25^{* * *}$ & $.13^{* * *}$ & -- & & \\
\hline 8. Number of Ideas Accepted & $.51^{* * *}$ & $.08^{* * *}$ & $.14^{* * *}$ & $.05^{* *}$ & $.36^{* * *}$ & $.06^{* * *}$ & $.24^{* *}$ & & \\
\hline 9. Position & $.10^{*}$ & $.09^{* * *}$ & $.16^{* * *}$ & $.04^{*}$ & $.35^{* * *}$ & .03 & .03 & .02 & -- \\
\hline 10. Region (HQ vs non-HQ) & .09 & $-.05^{* *}$ & $.05^{* *}$ & .01 & $.31^{* * *}$ & .03 & $.19^{* *}$ & $.18^{* * *}$ & $.17^{* * *}$ \\
\hline
\end{tabular}

$* \mathrm{p}<.05, * * \mathrm{p}<.01, * * * \mathrm{p}<.001$

\subsection{Logistic regression}

Table 2 summarizes the prediction results of the logistic regression, used to answer RQ1. Results showed that both idea attributes and contributor attributes predicted the likelihood of an idea being accepted. The overall model was quite good in predicting the degree of variability in the data. The significant chi-square indicated that the model fit significantly better than the empty model with just the constant. Further, the pseudo- $\mathrm{R}^{2}$ (using Nagelkerke r-squared) was .538 , indicating that the model explained about $54 \%$ of the variance in idea acceptance.

Table 2. Logistic Regression of Idea and Contributor Attributes on Idea Status.

\begin{tabular}{|c|c|c|c|c|c|c|}
\hline & B & S.E. & Wald & df & Sig. & $\operatorname{Exp}(\mathbf{B})$ \\
\hline Number of Likes & 1.27 & .41 & 9.63 & 1 & $.002 * *$ & 3.55 \\
\hline Duration & .33 & .13 & 6.67 & 1 & $.01 * *$ & 1.40 \\
\hline Number of Comments & -.03 & .01 & 8.34 & 1 & $.004 * *$ & .97 \\
\hline Number of Followers & .35 & .26 & 1.76 & 1 & .19 & 1.41 \\
\hline Expertise Level & .25 & .67 & .13 & 1 & .72 & 1.28 \\
\hline Number of Ideas Created & -.09 & .02 & 17.16 & 1 & $.00 * * *$ & .91 \\
\hline Accepted Ideas & 1.03 & .13 & 60.37 & 1 & $.00 * * *$ & 2.80 \\
\hline Position & .00 & .00 & 7.12 & 1 & $.008^{* *}$ & 1.00 \\
\hline Region (HQ vs non-HQ) & .81 & .37 & 4.88 & 1 & $.03 *$ & .45 \\
\hline Constant & -5.32 & 2.61 & 4.16 & 1 & $.04 *$ & .01 \\
\hline
\end{tabular}

In terms of idea-related attributes, the most significant predictor was the number of likes an idea had. The coefficient of 1.27 indicates that for each additional like, the log odds of acceptance (versus rejection) of the idea increased by 1.27. Further, ideas with longer duration of development were also more likely to be accepted. Finally, number of comments was a significant but negative predictor, indicating that ideas with more comments were less likely to be accepted. In terms of contributor attributes, the strongest predictor was the number of prior accepted ideas a contributor had. The number of total ideas contributed also had a significant effect, although it was negative, indicating that those with more ideas were less likely to have an idea accepted. Position and region of the contributor were also significant 
predictors, although position (status) of the contributor had little effect. Being from headquarters significantly increased the odds of having an idea accepted. The number of followers a contributor had and his/her expertise level in the tool were not significant. To further explore the degree to which ideation crossed hierarchical boundaries, we examined the mean number of ideas contributed and accepted by region, position, and expertise level within the tool. Our comparison of means reveals that employees from headquarters contributed the most ideas overall, and that they had the highest mean number of accepted ideas by far (see Table 3). A one-way ANOVA confirmed that these differences by region were significant $(F=30.364, p<.001, d f=9$ for total ideas; $F=20.686, p<.001, d f=9$ for accepted ideas).

Table 3. Mean Number of Total Ideas and Accepted Ideas by Region.

\begin{tabular}{|l|c|c|l|c|c|}
\hline Region & $\begin{array}{c}\text { Mean } \\
\text { Number } \\
\text { of Total } \\
\text { Ideas }\end{array}$ & $\begin{array}{c}\text { Mean } \\
\text { Number of } \\
\text { Accepted } \\
\text { Ideas }\end{array}$ & Region & $\begin{array}{c}\text { Mean } \\
\text { Number } \\
\text { of Total } \\
\text { Ideas }\end{array}$ & $\begin{array}{c}\text { Mean } \\
\text { Number of } \\
\text { Accepted } \\
\text { Ideas }\end{array}$ \\
\hline HQ & 13.13 & .83 & Northwest & 6.96 & .54 \\
\hline Chernozem & 8.59 & .00 & Siberia & 4.71 & .21 \\
\hline Central & 4.79 & .16 & South & 10.05 & .42 \\
\hline Far East & 5.56 & .10 & Ural & 10.34 & .40 \\
\hline Moscow & 9.07 & .11 & Volga & 5.61 & .21 \\
\hline
\end{tabular}

Further, top management was not the biggest contributor in terms of number of ideas (which was highest for middle management and retail specialists), but top managers had a much higher number of accepted ideas overall than lower-level employees. A one-way ANOVA confirmed that differences by position were also significant $(\mathrm{F}=12.508, \mathrm{p}<.001$, $\mathrm{df}=4$ for total ideas; $\mathrm{F}=9.064, \mathrm{p}<.001, \mathrm{df}=4$ for accepted ideas). Interestingly, although expertise level within the tool was not a significant predictor of idea acceptance in the logistic regression when other variables were controlled for, those with the highest level of expertise contributed a much higher number of total ideas as well as accepted ideas than less active users. A one-way ANOVA confirmed that differences by expertise level were significant $(\mathrm{F}=20.426, \mathrm{p}<.001, \mathrm{df}=3$ for total ideas; $\mathrm{F}=4.367, \mathrm{p}<.01$, df $=3$ for accepted ideas). This makes sense given that TeleCom Life was initially implemented by top management and then rolled out to lower-level employees in other locations (Table 4).

Table 4. Mean Number of Total Ideas and Accepted Ideas by Position and Expertise Level.

\begin{tabular}{|l|c|c|l|c|c|}
\hline Position & $\begin{array}{c}\text { Mean \# } \\
\text { Total } \\
\text { Ideas }\end{array}$ & $\begin{array}{c}\text { Mean \# } \\
\text { Accepted } \\
\text { Ideas }\end{array}$ & $\begin{array}{l}\text { Expertise } \\
\text { Level }\end{array}$ & $\begin{array}{c}\text { Mean \# } \\
\text { Total } \\
\text { Ideas }\end{array}$ & $\begin{array}{c}\text { Mean \# } \\
\text { Accepted } \\
\text { Ideas }\end{array}$ \\
\hline Top Mgmt & 5.98 & 1.17 & Level 4 & 8.52 & .36 \\
\hline Middle Mgmt & 9.69 & .33 & Level 3 & 1.32 & .03 \\
\hline $\begin{array}{l}\text { Senior } \\
\text { Specialist }\end{array}$ & 5.66 & .27 & Level 2 & 1.22 & .00 \\
\cline { 1 - 3 } Specialist & 8.31 & .35 & Level 1 & 1.00 & .00 \\
\cline { 1 - 2 } Support Staff & 7.28 & .33 & & & \\
\hline
\end{tabular}

\section{Discussion}

Social media is often heralded for its open architecture and resulting participatory culture. ESM offers new affordances for participatory decision-making in organizations, especially those that are large and geographically distributed, by providing a centralized forum to generate, evaluate, and prioritize new ideas that are contributed by employees from all 
levels and locations within the organization. Our findings shed light on which factors drive idea acceptance in a large Russian telecommunications company. We find that both idea attributes and contributor attributes predict which ideas are adopted.

Our findings suggest that idea attributes play a role in their likelihood of acceptance. We found that ideas were more likely to be accepted if they received more "likes" on the social media platform but fewer comments. This is consistent with how votes work to surface best answers in a community Q\&A (e.g. [22]), and the lesser number of comments may indicate less convolution of the original idea. Put another way, ideas with more comments may be more controversial and require more discussion, generating more negative feedback that ultimately results in their rejection. Successful ideas did, however, have a longer duration from initial posting to final comment, than did unsuccessful ones, implying that more deliberation time increases the likelihood of idea acceptance.

Our findings also highlight the importance of contributor attributes. We found that ideas were more likely to be accepted if the contributor was from the head office and closer to key decision makers, alluding to the network proximity effect. In addition to location, position also played a role as top managers did not contribute as many ideas overall, but the ideas they did contribute were significantly more likely to be accepted as those of lowerlevel employees. This is likely to be explained by the fact that top managers and other employees who are located in proximity to management in the headquarters location may be more aware of the decision-making process and have more opportunity to advertise their ideas due to their access to key decision makers, thus ultimately having a greater chance of having their ideas accepted and adopted. This pattern seems to perpetuate itself, as those with a greater track record of having ideas accepted are much more likely to have a future idea accepted. These results are interesting in light of the democratic claims often made about social media, as they serve to temper this discussion. Our findings suggest that rather than being truly democratic and decentralized, ideation in ESM is driven by those in (or proximate to) organizational positions of power. This - as well as the fact that management made the final decisions about idea acceptance or rejection - suggests that a hierarchy of decision-making persists despite the fact that all employees have access and ability to contribute ideas, such that all ideas are not truly created equal in social media applications but are dependent on the status level of their contributors.

\subsection{Practical implications}

Our study highlights a new and arguably successful use of ESM for the important work activity that is ideation. Organizations that have been apprehensive about deploying ESM can take note of the benefits that may accrue from the unique affordances of ESM. Even the "socialness" of ESM can be helpful in building relationships and gaining trust among employees [7], which should translate into productive uses of the tool. For ideation, ESM can be a tool that enables greater idea production without requiring participants to be collocated, synchronous, or spontaneous. While a greater quantity should increase the chance of getting a good idea, the affordances of ESM, such as metavoicing and the embedded social network, are more likely to ensure that it happens. Decision makers can also leverage the metadata from ESM to assist them in deciding which ideas to accept or reject. Employees, having direct access to the system, should be able to know the types of ideas that are more or less likely to be accepted, and modify their contribution along that path. 


\subsection{Limitations and future work}

The results, however, need to be read with certain limitations in mind, namely that this research is based on a single case study that may not generalize due to its boundary conditions of industry (telecommunications workers may be more technologically savvy), generation (primarily young retail employees in their 20s), and culture (workplace norms may be different in Russia than anywhere else). Future research should examine ESMbased ideation in other organizational and cultural contexts. Further, understanding of our data may be limited as we did not have complete textual content (only tags for a subset of posts) and had to contend with a language barrier. A second limitation is that this study is about ESM and less about public social media. While there may be overlap in the functionality of each, the circumstances and context surrounding the use of ESM are different than public tools such as Facebook and Twitter. Given that most research has focused on public tools, however, our study makes an important contribution to knowledge of ESM use for Q\&A and ideation in the workplace, about which less is known. Moreover, these findings should be equally applicable and relevant for decision-makers in any social sites that ask for ideas, or those attempting to find the proverbial needle in the haystack, in trying to locate quality information within the vast amount that exists. As organizations are increasingly implementing ESM platforms, it is important to understand how knowledge is shared and more importantly, how it influences processes that facilitate idea generation, evaluation, and adoption within an ESM application.

\section{References}

1. K.I. Miller, P.R. Monge, AoM J, 29, 727 (1986).

2. C. Stohl, G. Cheney, MCQ, 14, 349 (2001).

3. T. Kelley, J. Littman, The Art of Innovation: Lessons in Creativity from IDEO, America's Leading Design Firm (2001).

4. M. Lüders, First Monday, 18, 8 (2013).

5. M.M. Skeels, J. Grudin, Proceedings of GROUP (2009).

6. J.W. Treem, S.L. Dailey, C. Pierce, Proc. of ICA Conference (2013).

7. N.B. Ellison, J.L. Gibbs, M.S. Weber, Am. Beh. Sc. (2013).

8. C. Lampe, J. Vitak, N. Ellison, Proceedings of CSCW (2013).

9. J.L. Gibbs, N. Rozaidi, J. Eisenberg, JCMC, 19, 102 (2013).

10. J.W. Treem, P.M. Leonardi, Comm. Yearbook, 36, 143 (2012).

11. J. DiMicco, D.R. Millen, W. Geyer, C. Dugan, B. Brownholtz, M. Muller, Proc. of CSCW (2008).

12. M.J. Brzozowski, T. Sandholm, T. Hogg, Proceedings of GROUP (2009).

13. J. Huh, L. Jones, T. Erickson, W.A. Kellogg, R.K.E. Bellamy, J.C. Thomas, Proc. of CHI (2007).

14. J.J. Gibson, The ecological approach to visual perception (1979).

15. I. Hutchby, Sociology, 35, 441 (2001).

16. A. Osborn, Applied imagination (1957).

17. R.A. Wolfe, J. Mgt. Studies, 31, 405 (1998)

18. D. Halpern, J.L. Gibbs, Comp. in Human Beh., 29, 1159 (2013).

19. A. Majchrzak, S. Faraj, G.C. Kane, B. Azad, JCMC, 19, 38 (2013)

20. R. Gray, N. Ellison, J. Vitak, C. Lampe, Proc. of CSCW (2013).

21. L.A. Adamic, J. Zhang, E. Bakshy, M. Ackerman, Proc. of $W W W$ (2008).

22. E. Agichtein, C. Castillo, D. Donato, A. Gionis, G. Mishne, Proc. of WSDM (2008). 